\title{
Transient Changes of Cortical Interhemispheric Responses After Repeated Caffeine Administration in Immature Rats
}

\author{
J. TCHEKALAROVA ${ }^{1,2}$, H. KUBOVÁ, P. MARE $\check{S}^{2}$ \\ ${ }^{1}$ Institute of Neurobiology, Bulgarian Academy of Sciences, Sofia, Bulgaria, ${ }^{2}$ Institute of \\ Physiology, Academy of Sciences of the Czech Republic, Prague, Czech Republic
}

Received January 6, 2011

Accepted October 5, 2011

On-line October 12, 2011

\begin{abstract}
Summary
Repeated postnatal caffeine treatment of rat pups led to transient developmental changes in cortical epileptic afterdischarges. To know if physiological cortical functions are also affected transcallosal evoked potentials were studied. Rat pups of the Wistar strain were injected daily with caffeine (10 or $20 \mathrm{mg} / \mathrm{kg}$ s.c.) from postnatal day (P) 7 to P11, control siblings received saline. Cortical interhemispheric responses were tested at P12, 18, 25 and in young adult rats. Amplitude of initial monosynaptic components was evaluated in averaged responses. Single pulses as well as paired and frequency (five pulses) stimulations were used. Developmental rules - highest amplitude of responses in 25-day-old rats, potentiation with paired and frequency stimulation present since P18 - were confirmed. Caffeine-treated rats exhibited transient changes: single responses were augmented in P25 if high stimulation intensity was used, paired-pulse and frequency responses were higher in experimental than in control animals at P12, the opposite change was observed in 18- and more markedly in 25-day-old rats. No significant changes were found in adult animals, monosynaptic transcallosal responses represent a simple and robust system. The developmental profile of described changes did not exactly correspond to changes in epileptic afterdischarges supporting the possibility that afterdischarges did not arise from early monosynaptic components of responses. In spite of transient nature of changes they can reflect delayed or more probably modified brain development.
\end{abstract}

\section{Key words}

Evoked potentials • Cerebral cortex • Caffeine • Development • Rat

\begin{abstract}
Corresponding author
P. Mareš, Department of Developmental Epileptology, Institute of Physiology, Academy of Sciences of the Czech Republic, Vídeňská 1083, CZ-14220 Prague 4, Czech Republic. E-mail: maresp@biomed.cas.cz
\end{abstract}

\section{Introduction}

Caffeine is among the most widely consumed neuroactive substances; it possesses strong stimulatory effects (Nehlig et al. 1992). In addition, it is used in neonatal medicine (Millar and Schmidt, 2004), and in particular, in the treatment of apneic episodes in premature infants (Comer et al. 2001). Therefore consequences of early postnatal administration of caffeine mostly focused on seizure susceptibility were studied. Convulsants suppressing GABAergic inhibition are less active in adult rats injected with caffeine at postnatal days (PD) 2-6 (Guillet 1995, Guillet and Dunham 1995) as well as in immature rats receiving caffeine at PD 7-11 (Tchekalarova et al. 2007). Decreased convulsant action of theophylline (a compound of aminophylline) acting as an antagonist of adenosine receptors was also found (Tchekalarova et al. 2007). Opposite effect, i.e. augmentation of convulsant potency was found for agonists of ionotropic glutamate receptors N-methyl-D-aspartate and kainic acid (Tchekalarova et al. 2010a). Because of these controversive results changes of epileptic afterdischarges elicited by low-frequency cortical stimulation were studied in our laboratory. An increased duration of afterdischarges was found in 12-, 18- and 25-day-old rats but not in young adults (Tchekalarova et al. 2006). The epileptic afterdischarges are characterized by spike-and-wave 
rhythm in the EEG and accompanying clonic seizures of head and forelimb muscles (Mareš and Kubová 2006). Spike-and-wave rhythm is generated by corticothalamocortical mechanism (Avanzini et al. 1992, Steriade 2005). It matures during the third postnatal week in rats (Mareš et al. 1982). To analyze what is the role of cerebral cortex in the changes of these epileptic phenomena we decided to study cortical interhemispheric (transcallosal) evoked potentials in rats after repeated caffeine administration. The first components (first positive and first negative wave - P1N1) represent a pure cortical phenomenon - monosynaptic activation of symmetrical area of the opposite hemisphere realized by callosal pathway; components with longer latency have different generators (Grafstein 1959, Chapman et al. 1998, Teskey and Valentine 1998) and are highly variable in freely moving rats. The monosynaptic components are stable therefore they can be used for evaluation of cortical excitability. In addition, simple potentiation phenomena paired-pulse potentiation and frequency potentiation can be demonstrated with these evoked responses. These phenomena not only give an information about a dynamics of cortical function but may also serve as a measure of cortical development - paired-pulse potentiation develops between postnatal days 12 and 18 whereas frequency potentiation was found only at P25 (Mareš et al. 1993). Single evoked responses as well as both types of potentiation were used in our laboratory to study changes induced by status epilepticus (Mareš et al. 2005). These studies demonstrated their validity as developmental indexes and therefore we used them in the present study.

\section{Methods}

\section{Animals}

The experiments were performed in male Wistar rats. The litters were formed from 10 male rat pups on postnatal day (P) 1 (day of birth was counted as day 0 ). The animals were kept with their mothers under standard conditions $(12 / 12 \mathrm{~h}$ light/dark cycle, temperature $22 \pm 1{ }^{\circ} \mathrm{C}$, humidity $50-60 \%$ ). Food and water were freely available with the exception of test periods. Weaning took place at the age of 28 days. The experiments were approved by Animal Care and Use Committee of the Institute of Physiology, Academy of Sciences of the Czech Republic to be in agreement with Animal Protection Law of the Czech Republic as well as European Community Council directives 86/609/EEC.

\section{Caffeine treatment}

Rat pups in each litter were randomly assigned to one control and two experimental groups. Starting at P7 the animals in the experimental groups received injections of caffeine (Sigma, St. Louis, MO, 10 or $20 \mathrm{mg} / \mathrm{kg}$ s.c. in a volume of $1 \mathrm{ml} / \mathrm{kg}$ b.w.) for 5 days. Control siblings were injected with the same volume of saline.

Surgery

Cortical stimulation and recording silver ball electrodes were implanted to young adult rats at the age of 60 days under pentobarbital anesthesia. Stimulation electrodes were placed over sensorimotor cortical area of the right hemisphere at coordinates $\mathrm{AP}+1$ and -1 ; L $2.5 \mathrm{~mm}$, recording electrodes over left hemisphere sensorimotor area (AP 0; L $2.5 \mathrm{~mm}$ ), parietal association area (AP 3; L $3 \mathrm{~mm}$ ), occipital visual area (AP 6; L $4 \mathrm{~mm}$ ) - and an occipital electrode also over the right hemisphere. Reference electrode was inserted into nasal bone, grounding electrode over cerebellum. The electrodes were connected to a female plug and the whole assembly was fixed to the skull by means of two screws and dental acrylic. The experiment was performed after one-week rest, i.e. at P 67.

Epidural silver flat electrodes were implanted to rat pups on the day of experiment (P12, P18 or P25) under ether anesthesia. Coordinates for electrodes were calculated from adult values using bregma-lambda distance as reference value. Surgery lasted 10-12 min, the animals were allowed to recover for at least one hour and only then the experiments started.

\section{Stimulation and recording}

Stimulator with constant current output was used to deliver 1-ms biphasic pulses. Single pulses with intensities increasing stepwise from $0.2 \mathrm{~mA}$ were used to estimate threshold for elicitation of a clear-cut response, then two and three times this intensity was also used. The threshold found during this stimulation series served as a background for two-times threshold intensity applied for paired and frequency stimulations. Paired pulses were applied with interpulse intervals of $20,50,70,100,125$, 160, 200, 250, 300, 350, 400, 500, 750 and $1000 \mathrm{~ms}$. Frequency stimulation was formed by five pulses with interpulse intervals of 100, 125, 160, 200 and/or $300 \mathrm{~ms}$. Responses were amplified, digitalized at a rate of $1 \mathrm{kHz}$ and saved on a harddisc of the system (Kaminskij Biomedical Systems, Prague). Eight responses were always averaged and the amplitude difference between 


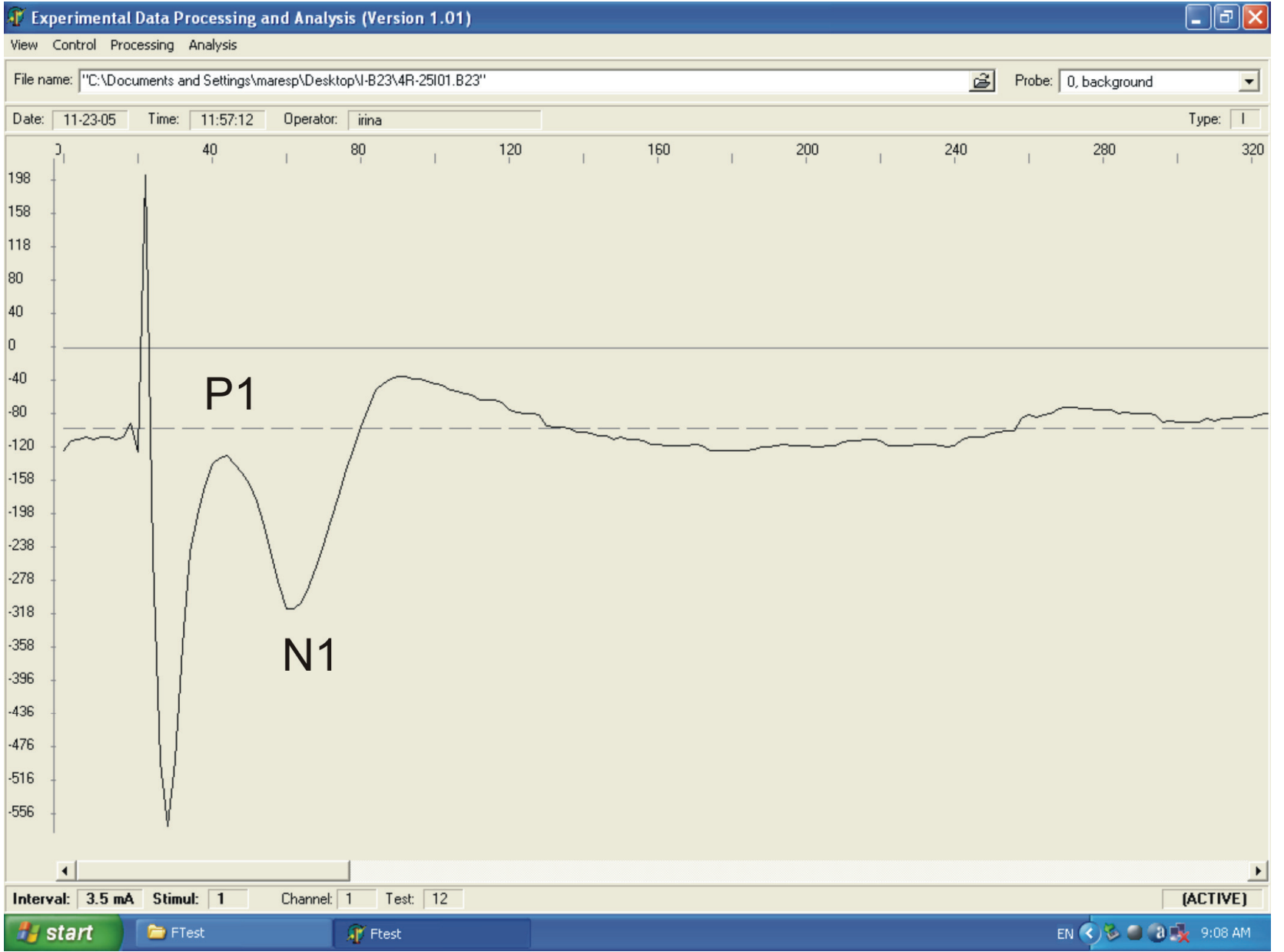

Fig. 1. Averaged cortical interhemispheric response from a 25-day-old rat. Waves P1 and N1 are marked to show what was evaluated. The whole curve represents $20 \mathrm{~ms}$ before and $300 \mathrm{~ms}$ after stimuli. Amplitude scale on the left in microvolts.

peaks of the first positive (P1) and first negative (N1) waves of the response was evaluated and their latency was measured (Fig. 1). The amplitude of the first response in the paired-pulse and frequency paradigm was taken as $100 \%$ and the relative amplitude of subsequent responses was calculated.

\section{Statistics}

The data were analyzed by a two-way analysis of variance (ANOVA) with factors age (only immature animals were compared) and treatment followed by a post-hoc Tukey's test (SigmaStat ${ }^{\circledR}$ SPSS). The level of significance was set at $\mathrm{p}<0.05$.

\section{Results}

\section{Single responses (Fig. 2)}

The amplitude of the initial positive and negative components of the interhemispheric responses elicited by threshold intensity of stimulation was influenced by the age (amplitude was higher in P25 rats than in the other age groups $[\mathrm{F}(3,108)=5.85, \mathrm{p}<0.001]$ but not by caffeine treatment. Furthermore, two-way ANOVA revealed age by treatment interaction $[\mathrm{F}(6,108)=2.659, \mathrm{p}=0.02]$. Comparison for age factor within group treated with the $20-\mathrm{mg} / \mathrm{kg}$ dose of caffeine also showed a significant increase of amplitude at P25 vs. P12 and P18 ( $<0.001)$.

Stimulation with two times threshold intensity demonstrated age by treatment interaction $[F(6,110)=2.189, p=0.045]$. Comparison for age factor within the $20-\mathrm{mg} / \mathrm{kg}$ caffeine group again showed significantly higher amplitude in P25 rats than in the other two age groups.

Stimulation with the three times threshold intensity resulted in significant effects of both factors (age and caffeine treatment) on amplitude of P1N1 complex $[\mathrm{F}(3,108)=6.6, \mathrm{p}<0.001]$ and $[\mathrm{F}(2,108)=4.93$, $\mathrm{p}=0.009]$, respectively. Two way ANOVA revealed age by treatment interaction $[\mathrm{F}(6,107)=3.61, \mathrm{p}=0.003)$. Post$h o c$ analysis showed an augmentation of responses as a result of caffeine treatment in $\mathrm{P} 25 \mathrm{rats}(10-\mathrm{mg} / \mathrm{kg}$ group $\mathrm{p}=0.002,20-\mathrm{mg} / \mathrm{kg}$ group $-\mathrm{p}=0.003)$. 


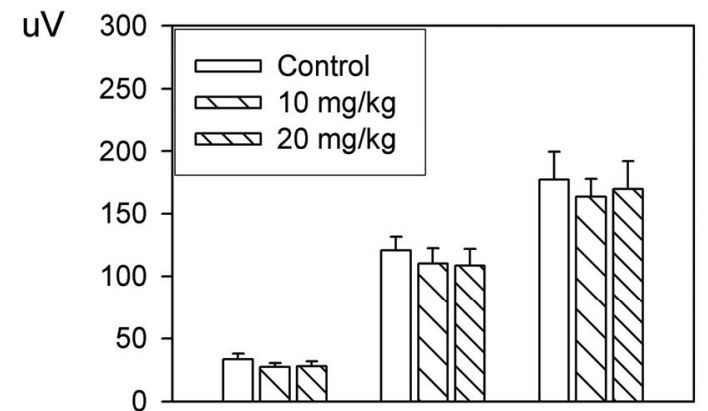

12
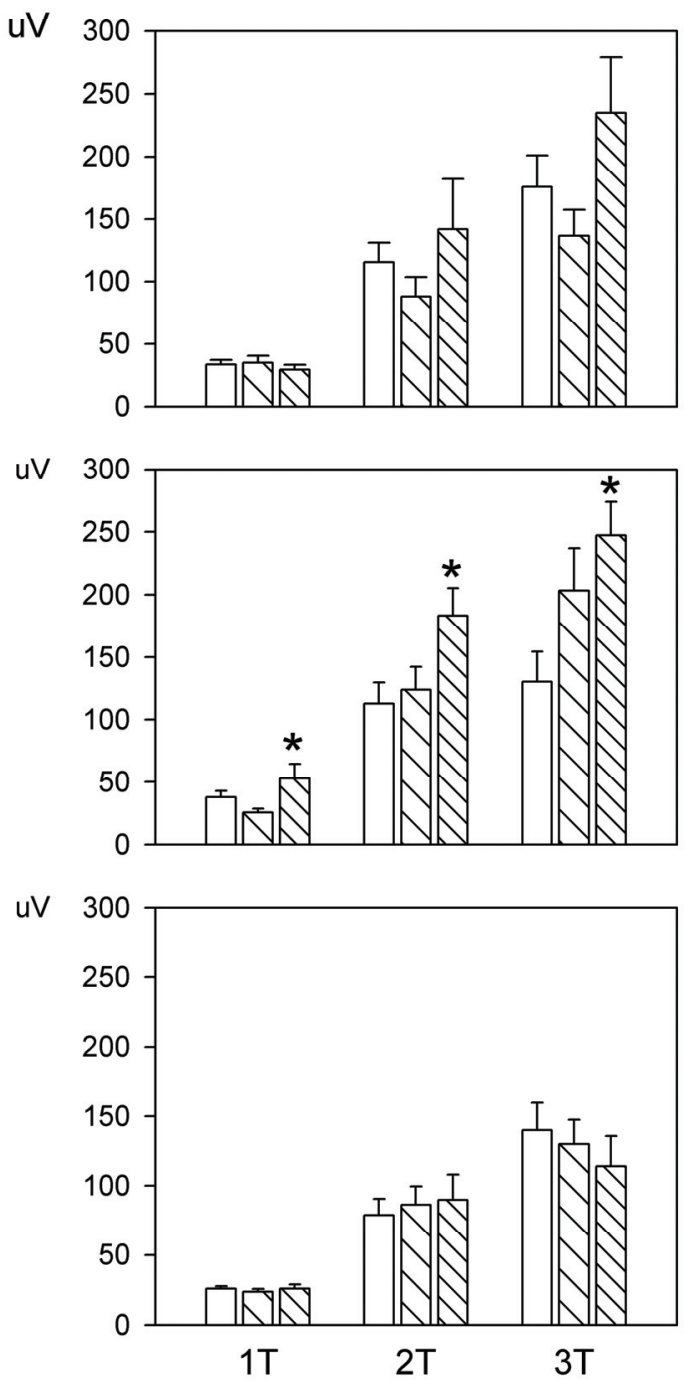

Fig. 2. Single interhemispheric (transcallosal) responses. Amplitude of the initial positive-negative complex of the interhemispheric responses of 12-, 18-, 25- and 60-day-old rats (from top to bottom). Abscissae - stimulation with threshold (1T), two (2T) and three (3T) times threshold current intensities; ordinates - amplitude in milivolts. Individual columns - see inset. Asterisks denote significant difference in comparison with the corresponding responses in control animals. See the transient increase in amplitude of responses at the age of 25 days in a group with $20-\mathrm{mg} / \mathrm{kg}$ doses of caffeine.

Latencies of either wave did not significantly differ among age groups and they were not changed in caffeine-pretreated animals.
Paired-pulse responses (Fig. 3)

Under control conditions, ratio of the second (testing) to the first (conditioning) response varied as a function of age. The youngest group (P12) exhibited only paired-pulse depression, the amplitude of the testing response did never exceed the amplitude of the conditioning one. Paired-pulse potentiation was present with short interstimulation intervals in all older groups and its expression increased with age. The developmental differences were statistically significant in responses with the interpulse intervals from 50 to $200 \mathrm{~ms}$ and also 350 and $400 \mathrm{~ms}$. Maximal potentiation of the second response was reached with the two shortest interpulse intervals ( $143 \%$ in P18, $129 \%$ in P25 and $190 \%$ in P60).

Caffeine treatment effect on paired-pulse responses was demonstrated with the interpulse intervals of 160,200 and $250 \mathrm{~ms}[\mathrm{~F}(2,107)=3.18, \mathrm{p}=0.047$; $\mathrm{F}(2,109)=4.16, \quad \mathrm{p}=0.018 ; \quad \mathrm{F}(2,107)=2.99, \quad \mathrm{p}=0.049$, respectively]. Two-way ANOVA revealed age by treatment interaction with $100[\mathrm{~F}(6,107)=2.45 . \mathrm{p}=0.03]$, $200 \quad[\mathrm{~F}(6,109)=3.21, \mathrm{p}=0.006], \quad 300 \quad[\mathrm{~F}(6,107)=2.25$, $\mathrm{p}=0.045], \quad 400 \quad[\mathrm{~F}(6,107)=4.91, \quad \mathrm{p}<0.001] \quad$ and 500 $[\mathrm{F}(6,107)=3.5, \mathrm{p}=0.004] \mathrm{ms}$. Post-hoc analysis showed that caffeine treatment during P7-P11 elicited an enhancement of relative amplitude of the testing responses in $\mathrm{P} 12$ rats in $300-\mathrm{ms}(\mathrm{p}=0.012), 350-\mathrm{ms}$ $(\mathrm{p}=0.048)$, and $500-\mathrm{ms}$ intervals $(\mathrm{p}=0.007)$ in the $10-\mathrm{mg} / \mathrm{kg}$ group and in $300-\mathrm{ms}(\mathrm{p}=0.047)$ and $500-\mathrm{ms}$ intervals $(\mathrm{p}=0.048)$ in the $20-\mathrm{mg} / \mathrm{kg}$ group. On the contrary, paired-pulse depression was found in caffeinetreated 18- and 25-day-old animals. The depression was observed in both 18-day-old caffeine-treated groups with interpulse intervals $350(\mathrm{p}=0.048$ and 0.046 for 10 - and $20-\mathrm{mg} / \mathrm{kg}$ groups, respectively) and $400 \mathrm{~ms}$ ( $\mathrm{p}<0.001$ for both groups). Either caffeine-treated group of 25 days old rats exhibited paired-pulse depression at intervals of 200 ( $\mathrm{p}=0.033$ and 0.049 , respectively), $250 \quad(\mathrm{p}=0.029$ and 0.003 , respectively) and $500 \mathrm{~ms}(\mathrm{p}=0.027$ and 0.016 , respectively). In addition, there was a significant depression of the second response with 160-ms interval in the $20-\mathrm{mg} / \mathrm{kg}$ group of 25 -day-old rats $(\mathrm{p}=0.036)$. The only significant change in adult rats was an augmented potentiation of the second response with 100-ms interval in the $10-\mathrm{mg} / \mathrm{kg}$ group $(\mathrm{p}=0.002)$.

\section{Frequency responses (Fig. 4)}

Two-way ANOVA revealed age and treatment effects for the relative amplitude of the second response in intervals 100, 125, 160 and $200 \mathrm{~ms}$; and a treatment effect for $300 \mathrm{~ms}$. Age by treatment interaction was 

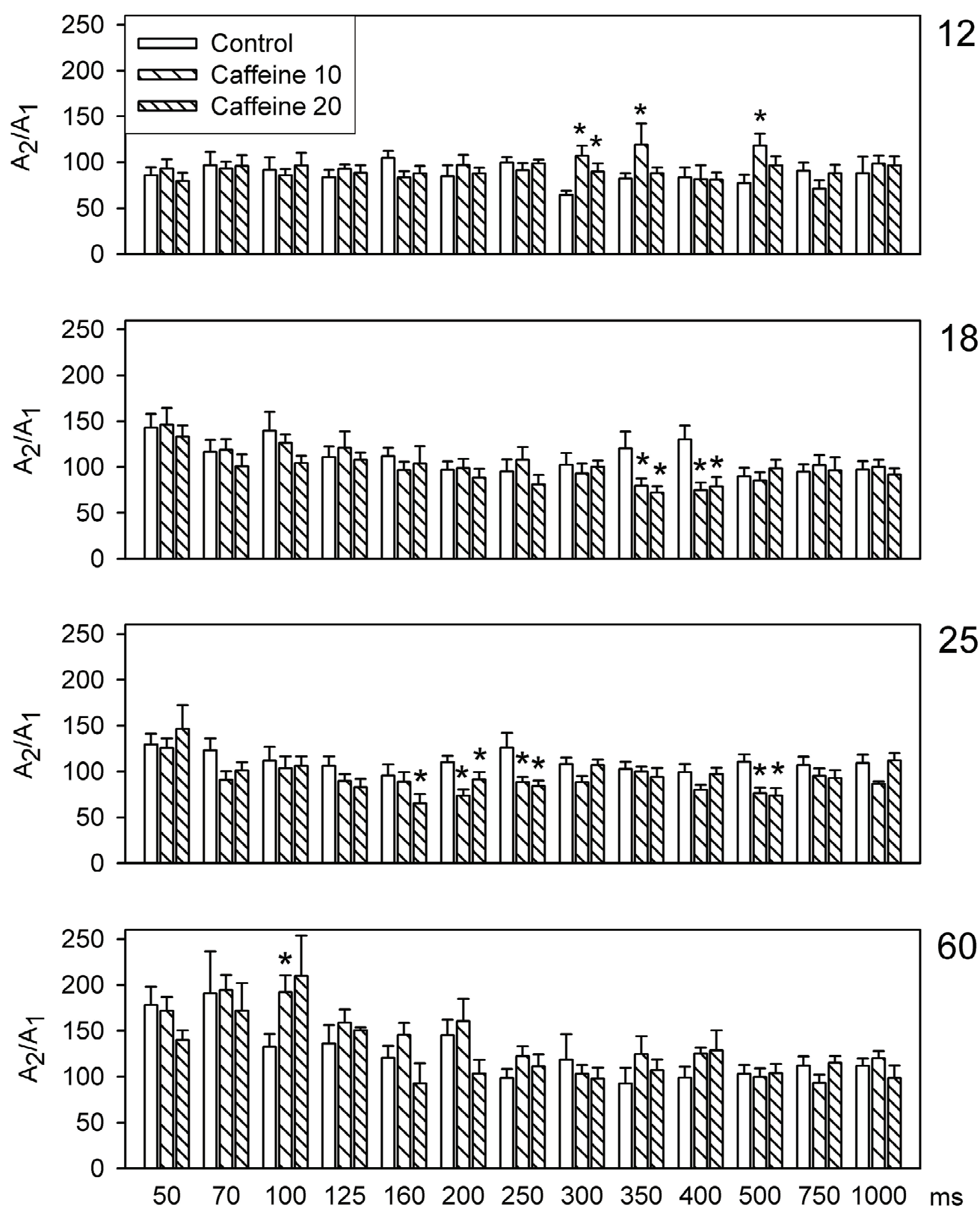

Fig. 3. Paired-pulse interhemispheric responses. Relative amplitude of the second (testing) response induced by paired-pulse stimulation. Abscissae - interpulse intervals; ordinates - ratio of the second to the first response. Other details as in Figure 1. Depression of the second response was found at some interpulse intervals in 18- and 25-day-old rats. 
12 days
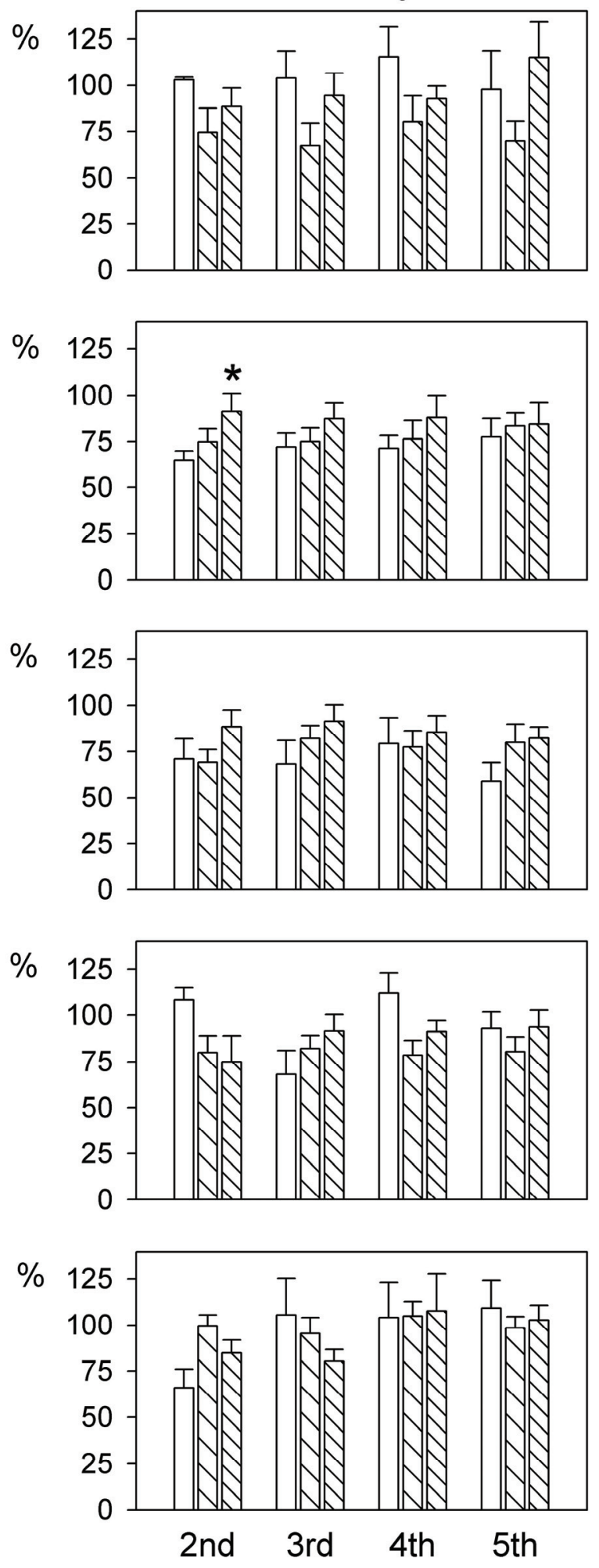

25 days

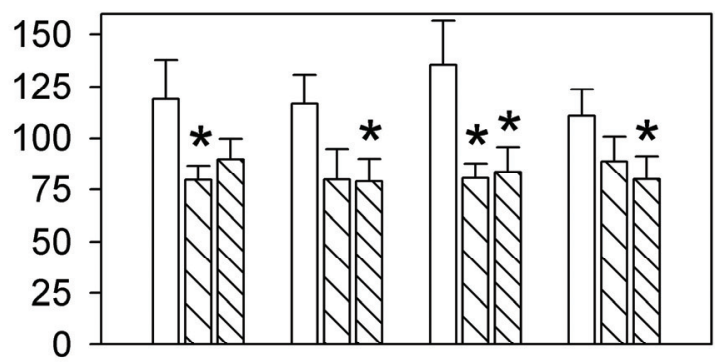

100

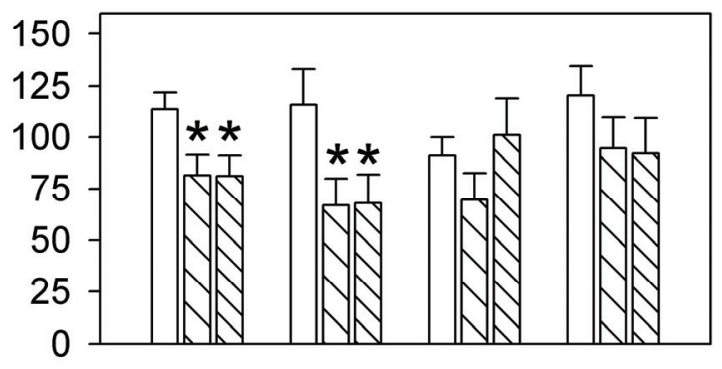

125

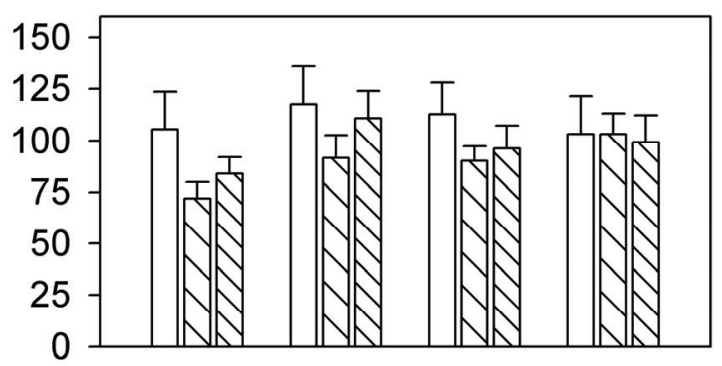

160

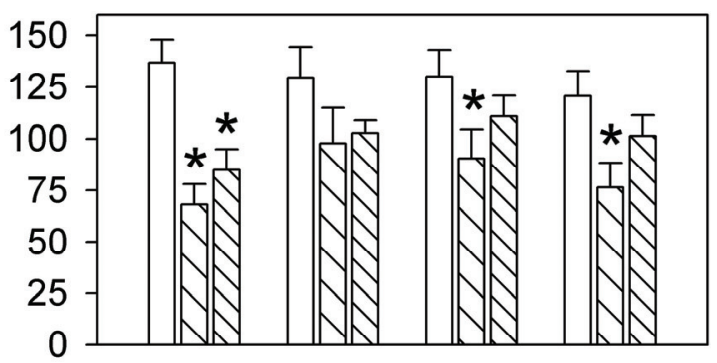

200

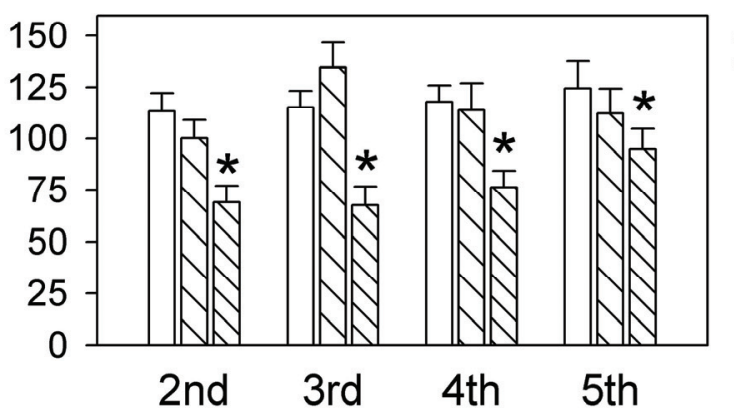

Fig. 4. Interhemispheric responses elicited by a series of five stimuli. Amplitude of the $2 \mathrm{nd}, 3 \mathrm{rd}$, 4th and 5 th response in relation to the amplitude of the first response taken as $100 \%$. Left column - rats 12 days old, right column - rats 25 days old. From top to botom: intervals between pulses 100, 125, 160, 200, and 300 ms. Other details as in Figure 1. The older group exhibits a suppression of frequency potentiation. 
registered in interpulse intervals 125,200 and $300 \mathrm{~ms}$. Post-hoc comparison demonstrated that there were no significant differences between control and caffeinetreated P12 animals with the exception of an increased ratio of the second to the first response at 300-ms interval in the $10-\mathrm{mg} / \mathrm{kg}$ group and at $125-\mathrm{ms}$ interval in the $20-\mathrm{mg} / \mathrm{kg}$ group (Fig. 3). The significant differences in P18 animals were only with the 160 -ms interval. Either dose of caffeine increased the ratio of the second, third and fifth response to the first one. Relative amplitude of the fourth response was significantly increased in the 10 - but not $20-\mathrm{mg} / \mathrm{kg}$ group (data not shown). Caffeinetreated 25-day-old rats exhibited a decrease of ratio of the second, third, fourth and fifth response to the first one. Level of statistical significance for the second response was reached with interstimulus intervals of 100,125 and $200 \mathrm{~ms}$ in the $10-\mathrm{mg} / \mathrm{kg}$ group and of 125,200 and $300 \mathrm{~ms}$ in animals receiving the higher dose. The third response was significantly decreased with intervals of $125 \mathrm{~ms}$ in the lower dose group and 100, 125 and $300 \mathrm{~ms}$ in the $20-\mathrm{mg} / \mathrm{kg}$ group. The decrease of the relative amplitude of the fourth response was significant with 100-ms interval in either dose group, with $200 \mathrm{~ms}$ in the lower and $300 \mathrm{~ms}$ in the higher dose group. Similar results were found for the fifth response only the depression with the 100-ms interval did not reach the level of significance in the 10-mg/kg group (Fig. 4).

There were no significant differences in adult animals (data not shown).

\section{Discussion}

Control animals in the present experimental series exhibited developmental changes as described in our previous studies - an increase in amplitude of responses and an appearance of paired-pulse potentiation between postnatal days 12 and 18 and frequency potentiation in the course of the third postnatal week (Mareš et al. 1993) as well as no marked changes in latencies (Mareš et al. 1975). Callosal connections of somatosensory cortical region are mature before the end of the second postnatal week as demonstrated morphologically (Wise and Jones 1976, Ivy and Killackey 1981) as well as electrophysiologically (Seggie and Berry 1973, Mareš et al. 1975, Wilson and Racine 1983). Later development of potentiation phenomena indicates an involvement of other connections maturing at different developmental stages - corticocortical and corticothalamic axons are born at different embryonic periods (Arimatsu and Ishida 2002). Ipsilateral corticocortical pathways mature during the third postnatal week (Nicolelis et al. 1991) or corticothalamic connections a little earlier (Scheibel et al. 1976). More complicated potentiation phenomena - short-term and long-term potentiation also appear duting the third week of postnatal life (after P16 and P18, respectively - Wilson and Racine 1983).

Repeated caffeine administration from P7 to P11 resulted in phasic changes expressed especially in paired-pulse and frequency potentiation. Augmentation of some responses in the 12-day-old animals might be due to overlasting presence of caffeine. Excitatory action of acute administration of caffeine was demonstrated since early postnatal stages (Holloway 1982). There are pharmacokinetic data demonstrating that catabolism of exogenous drugs is slow in the first two weeks of life of rats (e.g. Morselli 1983). In contrast to the youngest group, 18- and especially 25-day-old rats exhibited suppressed potentiation of paired and frequency responses. Failure of potentiation in these age groups might signify a developmental delay. Early components of transcallosal responses represent summation of excitatory postsynaptic potentials generated by activation of AMPA/kainate receptors (Chapman et al. 1998, Werk and Chapman 2003) therefore further analysis should be focused on this system. We cannot explain at present frequencydependent distribution of changes. Longer intervals which are affected in 12-day-old animals may reflect higher fatigability of responses in younger animals and a shift of changes to shorter interpulse intervals during the third and fourth postnatal week may be due to a decrease in fatiguability as demonstrated in classical studies (Mysliveček 1970, Rose and Ellingson 1970).

Cortical epileptic afterdischarges were changed differently in the 10 - and $20-\mathrm{mg} / \mathrm{kg}$ caffeine immature rats. Immature rats with lower dose of caffeine exhibited proconvulsant effect whereas postnatal administration of the 20-mg/kg dose resulted in higher thresholds and shorter duration of cortical afterdischarges. Differences between these effects and present results might be due to the fact that epileptic afterdischarges are formed on a basis of late components of evoked responses which were not analyzed in the present study. What was common for both studies was a transient nature of changes - at the age of 67 days no significant changes were observed. This developmental change is in agreement not only with cortical afterdischarges (Tchekalarova et al. 2006) but also with a 
decline of long-term potentiation after the $5^{\text {th }}$ postnatal week. It was demonstrated in auditory (Hogden and Dringenberg 2009) as well as visual cortex (Jang et al. 2009). In spite of transient nature of changes possible delay and/or more probably modification of brain development should be taken into account. Repeated postnatal caffeine administration modifies adenosine receptors (Guillet and Dunham 1985). Because A1 and A2A receptors which are present in the brain exhibit opposite effects, the final result is probably a complicated interplay of these two types of adenosine receptors.

\section{Conflict of Interest}

There is no conflict of interest.

\section{Acknowledgements}

This study was supported by a grant Nr. NR-9184/3 of the Grant Agency of Ministry of Health of the Czech Republic, by a ME08045 of the Ministry of Education of the Czech Republic, by a Research Project AV0Z 50110509 and by a mutual agreement between Czech and Bulgarian Academies of Sciences.

\section{References}

ARIMATSU Y, ISHIDA M: Distinct neuronal populations specified to form corticocortical and corticothalamic projections from layer VI of developing cerebral cortex. Neuroscience 114: 1033-1045, 2002.

AVANZINI G, DE CURTIS M, MARESCAUX C, PANZICA F, SPREAFICO R, VERGNES M: Role of the thalamic reticular nucleus in the generation of rhythmic thalamo-cortical activities subserving spike and waves. $J$ Neural Transm Suppl 35: 85-95, 1992.

CHAPMAN CA, TREPEL C, IVANCO TI, FROC DJ, WILSON K, RACINE RJ: Changes in field potentials and membrane currents in rat sensorimotor cortex following repeated tetanization of the corpus callosum in vivo. Cereb Cortex 8: 730-742, 1998.

COMER AM, PERRY CM, FIGGITT DP: Caffeine citrate: a review of its use in apnoea of prematurity. Paediat Drugs 3: 61-79, 2001.

GRAFSTEIN B: Organization of callosal connections in suprasylvian gyrus of cat. $J$ Neurophysiol 22: 504-515, 1959.

GUILLET R: Neonatal caffeine exposure alters seizure susceptibility in rats in an age-related manner. Dev Brain Res 89: 124-128, 1995.

GUILLET R, DUNHAM L: Neonatal caffeine exposure and seizure susceptibility in adult rats. Epilepsia 36: 743-749, 1995.

HOGSDEN JL, DRINGENBERG HC: Decline of long-term potentiation (LTP) in the rat auditory cortex in vivo during postnatal life: involvement of NR2B subunits. Brain Res 1283: 25-33, 2009.

HOLLOWAY WR JR: Caffeine: effects of acute and chronic exposure on the behavior of neonatal rats. Neurobehav Toxicol Teratol 4: 21-32, 1982.

IVY GO, KILLACKEY HP: The ontogeny of the distribution of callosal projection neurons in the rat parietal cortex. J Comp Neurol 195: 367-389, 1981.

JANG HJ, CHO KH, KIM HS, HAHN SJ, KIM MS, RHIE DJ: Age-dependent decline in supragranular long-term synaptic plasticity by increased inhibition during the critical period in the rat primary visual cortex. J Neurophysiol 101: 269-275, 2009.

MAREŠ P, KUBOVÁ H: Electrical stimulation-induced models of seizures. In: Models of Seizures and Epilepsy. PITKANEN A, SCHWARTZKROIN PA, MOSHÉ SL (eds), Elsevier, Amsterdam, 2006, pp 153-159.

MAREŠ P, MAREŠ J, KOZÁKOVÁ-MÁTLOVÁ E: Development of interhemispheric response in rats. T-I-T J Life Sci 5: 5-10, 1975.

MAREŠ P, MAREŠOVÁ D, TROJAN S, FISCHER J: Ontogenetic development of rhythmic thalamo-cortical phenomena in the rat. Brain Res Bull 8: 765-769, 1982.

MAREŠ P, SEIDL J, POHL M: Paired-pulse and frequency potentiation of cortical responses in developing rats. Brain Res Bull 32: 107-111, 1993.

MAREŠ P, TSENOV G, ALEKSAKHINA K, DRUGA R, KUBOVÁ H: Changes of cortical interhemispheric responses after status epilepticus in immature rats. Epilepsia 46 (Suppl 5): 31-37, 2005.

MILLAR D, SCHMIDT B: Controversies surrounding xanthine therapy. Semin Neonatol 9: 239-244, 2004. 
MORSELLI PL: Development of physiological variables important for drug kinetics. In: Antiepileptic Drug Therapy in Pediatrics. MORSELLI PL, PIPPENGER CE, PENRY JK (eds), Raven Press, New York, 1983, pp 1-12.

MYSLIVEČEK J: Electrophysiology of the developing brain - central and eastern european contributions. In: Developmental Neurobiology. HIMWICH WA (ed), C. Thomas, Springfield, IL, 1970, pp 475-527.

NEHLIG A, DAVAL J-L, GERARD D: Caffeine and the central nervous system: mechanisms of action, biochemical, metabolic and psychostimulant effects. Brain Res Rev 17: 137-170, 1992.

NICOLELIS MA, CHAPIN JK, LIN CS: Ontogeny of corticocortical projection of the rat somatosensory cortex. Somatosens Mot Res 8: 193-200, 1991.

ROSE GH, ELLINGSON RJ: Electrophysiology of the developing brain. In: Developmental Neurobiology. HIMWICH WA (ed), C. Thomas, Springfield, IL, 1970, pp 393-425.

SCHEIBEL ME, DAVIES TL, SCHEIBEL AB: Ontogenetic development of somatosensory thalamus. I. Morphogenesis. Exp Neurol 51: 392-406, 1976.

SEGGIE J, BERRY M: Ontogeny of interhemispheric evoked potentials in the rat: significance of myelination of the corpus callosum. Exp Neurol 35: 215-232, 1972.

STERIADE M: Sleep, epilepsy and thalamic reticular inhibitory neurons. Trends Neurosci 28: 317-324, 2005.

TCHEKALAROVA J, KUBOVÁ H, MAREŠ P: Biphasic effect of chronic postnatal caffeine treatment on cortical epileptic afterdischarges during ontogeny in rats. Brain Res 1082: 43-49, 2006.

TCHEKALAROVA J, KUBOVÁ H, MAREŠ P: Effects of postnatal caffeine exposure on seizure susceptibility in developing rats. Brain Res 1150: 32-39, 2007.

TCHEKALAROVA J, KUBOVÁ H, MAREŠ P: Postnatal caffeine treatment affects differently two pentylenetetrazol seizure models in rats. Seizure 18: 463-469, 2009.

TCHEKALAROVA J, KUBOVÁ H, MAREŠ P: Effects of early postnatal caffeine exposure on seizure susceptibility of rats are age- and model-dependent. Epilepsy Res 88: 231-238, 2010a.

TCHEKALAROVA J, KUBOVÁ H, MAREŠ P: Postnatal period of caffeine treatment and time of testing modulate the effect of acute caffeine on cortical epileptic afterdischarges in rats. Brain Res 1356: 121-129, $2010 \mathrm{~b}$.

TESKEY GC, VALENTINE PA: Post-activation potentiation in the neocortex of awake freely moving rats. Neurosci Biobehav Rev 22: 195-207, 1998.

WERK CM, CHAPMAN CA: Long-term potentiation of polysynaptic responses in layer V of the sensorimotor cortex induced by theta-patterned tetatnization in the awake rat. Cerebr Cortex 13: 500-507, 2003.

WILSON DA, RACINE RJ: The postnatal development of post-activation potentiation in the rat neocortex. Brain Res 283: 271-276, 1983.

WISE SP, JONES EG: The organization and postnatal development of the commissural projection of the rat somatic sensory cortex. J Comp Neurol 168: 313-343, 1976. 